\title{
BLACK BEARS IN THE WILD RETAIN MUSCLE STRENGTH DURING HibERNATION
}

\author{
HENRY J. HARLOW $\downarrow$ TOM LOHUIS \\ DEPARTMENT OF ZOOLOGY AND PHYSIOLOGY \\ UNIVERSITY OF WYOMING † LARAMIE
}

THOMAS D.I. BECK $\downarrow$ COLORADO DIVISION OF WILDLIFE $\downarrow$ DOLORES

\author{
PAUL A. IAIZZO \\ DEPARTMENTS OF ANESTHESIOLOGY AND PHYSIOLOGY \\ UNIVERSITY OF MINNESOTA \ MINNEAPOLIS
}

\begin{abstract}
$\uparrow$ ABSTRACT:
Back bears hibernating through the winter at near normal body temperatures $\left(34^{\circ} \mathrm{C}\right)$ have limited muscle disuse atrophy. Bears in their natural dens were fitted with a foot torque plate assembly to measure ankle dorsiflexion in response to supramaximal stimulation. Bears lost only $22 \%$ of their strength over a 130 day denning period which compares to a predicted $90 \%$ strength loss over the same period by humans either confined to bed rest or in a weightless environment. Additionally, six out of 8 muscle twitch parameters altered by muscle atrophy were unchanged by prolonged confinement. Understanding strength retention over an extended period of inactivity by bears has far reaching implications for human medicine and space travel.

\section{$\downarrow \quad$ INTRODUCTION}

Inactivity in humans, whether from confined bed rest, weightlessness or limb immobilization, leads
\end{abstract}

to skeletal muscle atrophy. Studies on animal models to characterize disuse and/or starvation induced muscle atrophy have shown: 1) reductions in muscle cell (fiber) numbers and size, 2) reductions in ratio of slow oxidative to fast glycolytic fibers, and 3) decreases in myofibrillar protein contents. These changes ultimately result in both a loss of muscle tone and impaired strength. The black bear may be a paradox. These animals remain within their winter den for 5 to 7 months at a near normal body temperature (about $34^{\circ} \mathrm{C}$ ). It is believed that during this time bears do not eat, drink, urinate, defecate or show appreciable activity. We have found that hibernating bears have elevated blood cortisol levels while in their dens (Harlow et al., 1990), but have low serum urea-creatinine ratios (Nelson, et al., 1984), suggesting that protein may be conserved during the winter. Our recent studies have confirmed this speculation by demonstrating that, in spite of prolonged starvation and confinement, overwintering bears do not exhibit appreciable skeletal muscle atrophy. We have taken muscle biopsies from denned 
bears during early and late winter to monitor changes in muscle morphology, protein content and protein turnover. Remarkably, these bears, under natural winter conditions, have no loss of skeletal muscle fiber number or size. Additionally, some muscles maintain their protein content and oxidative capacity while others show only a marginal $(14 \%)$ reduction in oxidative fiber ratio and protein (about 6-10\%) content (Tinker, et al., 1998). Our data on protein turnover even suggest that this protein conservation may increase as the winter progresses (unpublished data). In contrast, studies examining healthy patients after 1-6 weeks of muscle unloading or bed rest have shown muscle atrophy rates of $2-3 \%$ per week in whole muscle or fiber cross sectional area (Adams, et al., 1994). If a similar percentage of protein loss (about $0.4 \%$ per day) were to occur in bears, it would extrapolate to a reduction in excess of $50 \%$ over the winter. What makes this comparison even more remarkable is that, unlike human studies where patients receive nutrient intake, overwintering bears are in a state of starvation. Indeed, bears have an extraordinary capacity to hydrolyze urea and reaminate the nitrogen back into amino acids and consequent protein synthesis which may account for their high protein retention during the denning period (Nelson, et al., 1995).

A loss of muscle mass and protein is the major cause of decreased strength (Widrick et al., 1998). In spite of their confinement within a den, black bears are capable of rapid and sustained muscular activity when disturbed at any time during the winter. In view of our findings that bears do not appear to show typical signs of disuse atrophy and can exhibit locomotor prowess, we tested the critical hypothesis that bears, after prolonged starvation and immobility, retain muscle strength.

\section{$\downarrow \quad$ METHODS}

To test the above hypothesis, we monitored hind leg strength of bears during late fall, just after denning, and again during early spring prior to emergence from their dens. Muscle strength was measured using modified non-invasive force assessment techniques previously validated and employed in a clinical setting on humans to diagnose neuromuscular disorders, track weakness due to disease progression and evaluate efficacy of prescribed therapy (Sigg, et al., 1998). This technique allowed for a quantitative in vivo assessment of strength in bears with high reliability and quantitative capacity by measuring muscle contraction in response to supramaximal nerve stimulation (Brass, et al., 1990).

Adult bears $(\mathrm{N}=6)$ were captured using $2 \mathrm{x}$ $1.5 \times 1.5 \mathrm{~m}$ woven metal cage traps during the summer of 1998 in Middle Park Colorado $\left(40^{\circ} 5 \mathrm{~N}\right.$ $\left.105^{\circ} 55 \mathrm{~W}\right)$ elevation $2400 \mathrm{~m}$ and fitted with radiotelemetry collars (ATS, $150-160 \mathrm{MHz}$ range). These bears were tracked to their dens by snowshoe in November/December and again in March/April 1998-99 with an average of 130 days between sampling. The dens were excavated and bears anesthetized with Telazol $(7.0 \mathrm{mg} / \mathrm{kg})$ administered by a spring-operated jab pole. Bears were removed from their den, weighed to the nearest $100 \mathrm{gm}$ on a digital load scale (Dyna Link model MSI 7200), placed on a dry Thermarest pad and covered with a wool blanket. Body fat and lean body mass were calculated from resistance values obtained through the bear using a RJL model 101Q Bioelectrical Impedance Analyzer and equations previously validated on bears. The study bears were then rolled onto their side for measurement of muscle strength on the same leg during fall and spring using a strict protocol to insure comparison over this inactive winter period.

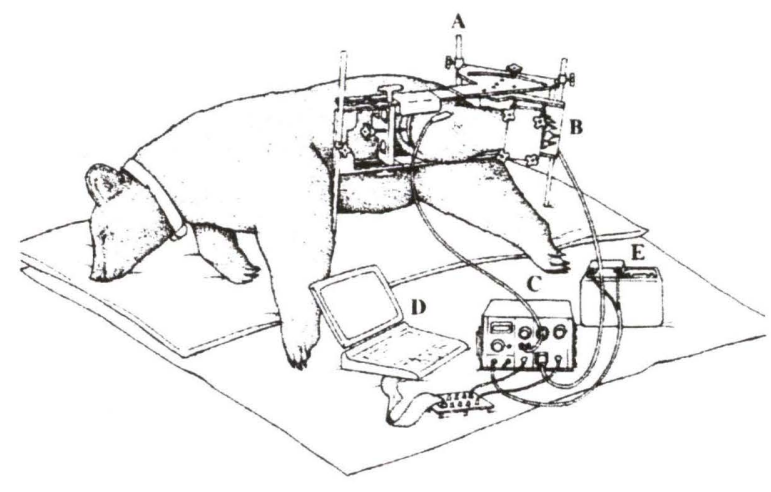

Figure 1. The force assessment muscle strength measurement system. Components consists of: A) stabilizing metal brace that holds the leg of the bear in a secure horizontal position, B) a foot plate with force transducer that detects the evoked torque produced by the electrically stimulated tibialis anterior, C) hardware devices for nerve stimulation, signal amplification, and signal conditioning, D) a computer for stimulus delivery and equipped with data acquisition software for recording, analyzing, and displaying all signals simultaneously, and E) battery power source. Stimuli were delivered to the common perineal nerve. Deformation of the foot plate assembly produced a strain gauge output proportional to the muscle induced torque from the tibialis anterior which was then amplified.

A rigid brace was secured to the bear's leg in a position which confined movement of ankle dorsiflexion (Figure 1). The foot was positioned such 
that the axis of rotation of the ankle joint approximated that of the footplate. The common perineal nerve was stimulated supramaximally (with DC pulses of $0.5 \mathrm{~ms}$ duration at a current of 10 milliamps and voltages varying between $100-250 \mathrm{~V}$ ) with surface silver/silver chloride electrodes positioned above the head of the fibula. The resulting torque on the footplate, from contraction of the tibialis anterior muscle, transferred force to an aluminum bar located below the plate instrumented with two strain gauges in a Wheatstone bridge configuration (Figure 1). A torque versus time graph was generated (Figure 2) as were numeric analyses of 8 additional parameters characterizing the contractive response. The test protocol was composed of two sections: 1) the ankle position was adjustable (in $10^{\circ}$ increments) to $40^{\circ}$ in either the plantarflexed or dorsiflexed direction (relative to a neutral ankle position) to find the optimal length of the muscle at which an evoked twitch attained maximal torque (ie. length-tension relationship) followed by, 2) maximal torque and contraction characteristics recorded in response to single and multiple pulses (double, triple and quadruple pulses with $5 \mathrm{msec}$ interpulse intervals).

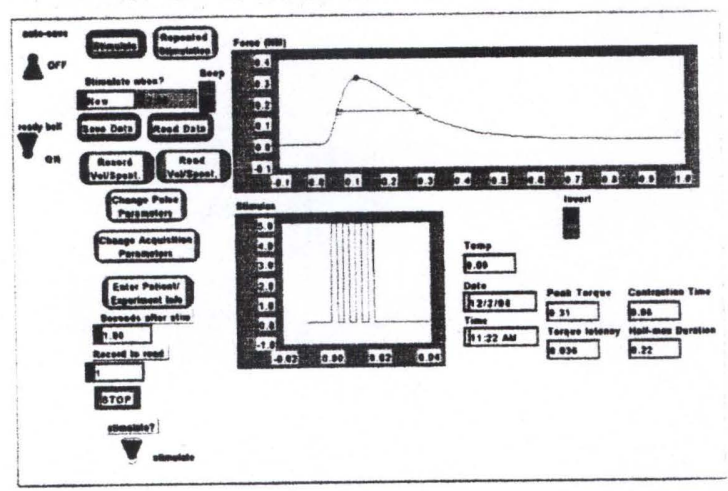

Figure 2. Graphically displayed are the muscle torque waveform (above) and, on an expanded time-scale, a quadruple pulse stimuli (below). Numerically displayed are the peak torque, and the adjustable controllers. Time 0 is the time of stimulation. The actual display shown is of the torque generated by the tibialis anterior muscle of a bear during the late winter.

Rectal temperatures were measured with alcohol thermometers and Atkins needle thermocouple probes (model 396K) were inserted deep into the muscles immediately after measuring strength in both the fall and spring. Interestingly, bears exhibit regional heterothermia with leg temperatures approximately $2^{\circ} \mathrm{C}$ lower than rectal temperature (Table 1). A temperature coefficient $\left(\mathrm{Q}_{10}\right)$ of 3.33 was determined on muscle contraction by measuring force of contraction and other parameters on the muscle at hibernation temperatures and then again at elevated temperatures of the muscle induced by wrapping the ankle with catalytic heat pads.

Table 1. Muscle and rectal temperature $\left({ }^{\circ} \mathrm{C}\right)$ of 6 bears in the fall and spring taken at the den site. Number in parenthesis is I SEM. Asterisk identifies significant difference from fall values at $P<.05$.

\begin{tabular}{|c|c|c|}
\hline & Muscle Temperature ( $\left.{ }^{\circ} \mathrm{C}\right)$ & Rectal Temperature $\left({ }^{\circ} \mathrm{C}\right)$ \\
\hline$\overline{\text { FALL }}$ & $32.8(.3)$ & $3+.6(.5)$ \\
\hline SPRING & *31.5(.2) & $3+4(.2)$ \\
\hline
\end{tabular}

\section{$\downarrow \quad$ RESULTS}

During the 130 days of hibernation, this group of bears lost approximately $24 \%$ of their body mass, of which the majority was fat (Table 2). There was only a $14 \%$ loss in lean body mass; comprised of bone, water, carbohydrate and protein material. Of the lean tissue reduction (Table 2) only a small fraction, about $1.7 \mathrm{~kg}$, would be represented by protein loss from skeletal muscle, visceral smooth muscle, albumin and extracellular protein matrix.

Table 2. Body mass, body fat and lean tissue $(\mathrm{Kg})$ changes as well as percent loss from fall to spring by 6 bears overwintering within their natural dens. Number in parenthesis is I SEM. Asterisks identify significant difference from fall values at $\mathbf{P}<.05$

\begin{tabular}{|c|c|c|c|}
\hline & Body Mass & Body Fat & Lean Tissue \\
\hline F.ALL (Kg) & $76.8(5.5)$ & $24.8(2.5)$ & $51.9(4.2)$ \\
\hline SPRING $(\mathrm{Kg})$ & $-58.5(4.0)$ & $14.2(1.9)$ & $444.1(3.2)$ \\
\hline Kg Loss & $18.3(1.9)$ & $10.7(1.0)$ & $7.8(0.9)$ \\
\hline$\%$ Loss & $23.7(1.7)$ & $44.0(4.7)$ & $14.3(1.2)$ \\
\hline
\end{tabular}

Strength was concomitantly retained in skeletal muscle. There was a progressive increase in peak torque force of the tibialis anterior in response to double, triple and quadruple pulse stimuli (Figure $3 \mathrm{~A})$. Additionally, there was only a $20-32 \%$ loss of strength in response to double, triple and quadruple pulses given at the beginning and end of the 130 days of den confinement. Importantly, the muscle temperature was significantly lower in the late winter tests compared to early winter monitoring on 5 of 6 bears (Table 1). Muscle temperature of one bear was higher in the later winter, perhaps due to its higher muscular activity in the den just prior to testing. As expected, temperature has an influence on peak twitch tension and time course parameters of twitch responses in humans and other animals (Iaizzo and Poppele, 1990). The temperature coefficient calculated on muscle activity of bears was consistent with that of other studies (Davies, et al., 1982). By compensating for this muscle temperature decrease or elevation from early to late winter, the actual loss of strength was only $8-23 \%$ from double to quadruple pulse stimuli, reflective of the retention of protein and muscle fiber integrity by overwintering bears. This was further exemplified by unaltered values of six of 
the eight characteristics of muscle contraction after temperature compensation over the 130 days of confinement. Only peak rate of twitch development and peak rate of decay exhibited noticeable alterations during the winter, which may suggest some modifications of muscle fiber type ratios over this period (Table 3).

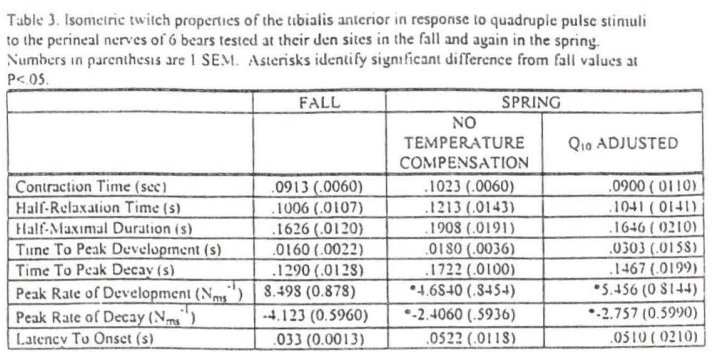

\section{$\uparrow$ DISCUSSION}

Immobility in humans results in a rapid and marked loss of strength. For example, muscle force assessed in lower limb extensor and flexor muscles of humans, under clinical conditions, exhibit about $0.7 \%$ loss of strength per day as a result of limb unloading, bed rest and space flight (Dudley, et al., 1989). Based upon these rates recorded for humans, it would be predicted that bears, after 130 days of inactivity would have about a $90 \%$ loss of strength with severely impaired locomotor ability. On the contrary, bears lost less than $25 \%$ strength and were highly mobile when disturbed during the winter.

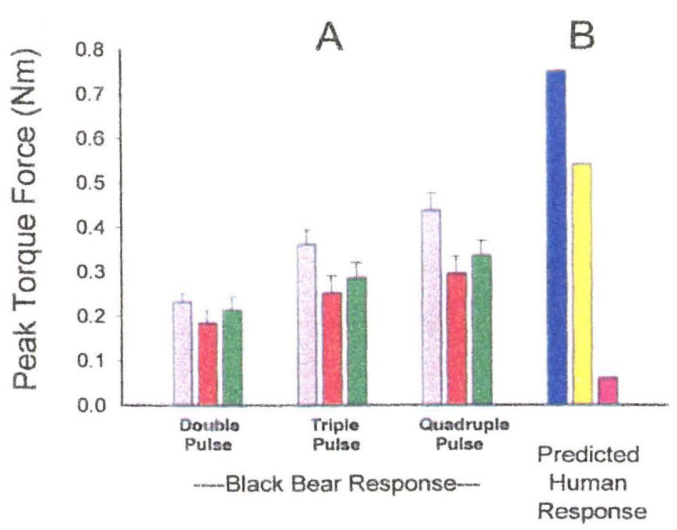

Figure 3. (A) Peak torque force $(\mathrm{Nm})$ of the tibialis anterior in response to a double, triple and quadruple pulse stimuli to the perineal nerve for 6 bears tested at their den site in the fall and again in the spring. Grey bars depict bears in the fall at an average muscle temperature of $32.8^{\circ} \mathrm{C}$. Red bars represent spring bears at an average muscle temperature of $31.5^{\circ} \mathrm{C}$ while green bars represent spring bears adjusted for an average temperature difference of $1.3^{\circ} \mathrm{C}$ (a temperature coefficient of 3.33). Vertical lines are 1 SEM. (B) Peak torque force $(\mathrm{Nm})$ of ankle dorsiflexion in healthy humans using a similar apparatus and protocol to the one in this study. The blue bar represents measured strength at a muscle temperature of $34.2^{\circ} \mathrm{C}$. The yellow bar is the predicted strength at a leg temperature of $31.5^{\circ} \mathrm{C}$ if influenced strictly by a temperature effect while the purple bar is the predicted strength of humans after 130 days of atrophy at $0.7 \%$ strength loss per day.
What would account for the retention of muscle mass and strength by inactive bears? Of course there is the reduction in metabolic demands as a result of lower body temperature. However, bears enter only mild hypothermia with body core temperatures just $4^{\circ} \mathrm{C}$ below that of active humans (Table 1). As an example, humans tested on an apparatus similar to that used in this study have strength values of about $0.75 \mathrm{Nm}$ (Quinlan, et al., 1989) for ankle dorsiflexor twitch at a muscle temperature of $34.2^{\circ} \mathrm{C}$ (Figure $3 \mathrm{~B}$ ). This value is very close to that predicted for bears at a similar temperature. It would be expected that strength in humans would drop to only $0.54 \mathrm{Nm}$ at a muscle temperature comparable to that of spring hibernating bears $\left(31.5^{\circ} \mathrm{C}\right)$ if solely influenced by a temperature effect (Figure 3B). However, if strength loss due to atrophy continues at $0.7 \%$ per day, a peak torque force of only $0.0675 \mathrm{Nm}$ would be expected after 130 days of inactivity (Figure 3B). Bears retained values around $0.4 \mathrm{Nm}$ under these conditions. Therefore, temperature related metabolic depression can account for only a portion (about 20\%) of the overall strength retention observed in overwintering bears. Alternate avenues must also be used, such as conservation of protein nitrogen through urea hydrolysis (Nelson, et al., 1975) and use of labile protein reserves like visceral smooth muscle and extracellular matrix. But, loss of contractile protein appears to explain only about two thirds of the strength loss of bed rest patients (Berg, et al., 1997). Among candidates to explain the remaining loss of strength are alterations in neural drive (McComas, 1994) and forcegenerating capacity of muscle (Berg and Tesch, 1996). These properties may be retained by bears through subtle muscle stimulation to elicit shivering and isometric contraction throughout the winter. We are presently directing our efforts on investigating muscle activity in hibernating bears to understand cellular mechanisms of force generation and neural enervation as well as focusing attention on alternate sources of labile protein reserves. The force retention by bears denned at near normal body temperatures for over 130 days is most striking when considering that this is also a period without food intake. Discerning these processes in hibernating bears promises to have long reaching impact in studies of muscle disorders, prolonged bed rest, and sports medicine, as well as antigravity and long distance space travel by humans. 


\section{LITERATURE CITED}

Adams G.R., B.M. Hather, G.A. Dudley. 1994. Effect of short-term unweighting on human muscle strength and size. Aviation \& Space Environmental Medicine 65:1116-1121.

Berg, L. H.E., Larsson, P.A. Tesch. 1997. Lower limb skeletal muscle function after 6 wk of bed rest. Journal of Applied Physiology. 82:182-188.

Berg, H.E. and P.A. Tesch. 1996. Changes in muscle function in response to 10 days of lower limb unloading in humans. Acta Physiologica Scandinavia 157:63-70.

Brass, T.J. M.K.H. Loushin, J.W. Day, P.A. Iaizzo. 1990. An improved method for muscle force assessment in neuromuscular disease. Journal of Medical and Engineering Technology 20:67-74.

Davies, C.T., I.K. Mecrow, M.J. White. 1982. Contractive properties of the human triceps surae with some observations on the effects of temperature and exercise. European Journal of applied Physiology 49:255-261.

Dudley, G.A., M.R. Duvoisin, V.A. Convertino, P. Buchanan. 1989. Alterations of the in vivo torque-velocity relationship of human skeletal muscle following 30 days exposure to simulated microgravity. Aviation \& Space Environmental Medicine 60:659-663.

Harlow, H.J., T.D.I. Beck, L.M. Walters, S.S. Greenhouse. 1990. Seasonal serum glucose progesterone, and cortisol levels of black bears (Ursus americanus) Canadian Juornal of Zoology 68:183-187.

Iaizzo, P.A. and R.E. Poppele. 1990. Twitch relaxation of the cat soleus muscle at different lengths and temperatures. Muscle \& Nerve 13:1105-1112.
McComas, A.J. 1994. Human neuromuscular adaptations that accompany changes in activity. Med. Sci. Sports Exercise 26:14981509.

Nelson, R.A. J.D. Jones, H.W. Wahner, D.B. McGill, C.F. Code. 1975. Nitrogen metabolism in bears: urea metabolism in summer starvation and in winter sleep and ole of urinary bladder in water and nitrogen concentration Mayo Clinic Proceedings 50:141-146.

Nelson, R.A.. T.D.I. Beck, D.L. Steiger. 1984. Ratio of serum urea to serum creatine in wild black bears. Science 226:841-842.

Quinlan, J.G. P.A. Iaizzo, E.H. Lambert and G.A. Gronert. 1989. Ankle dorsiflexor twitch properties in malignant hyperthermia. Muscle and Nerve 12:119-125.

Sigg, D.C., K.I. Hasinoff, P.A. Iaizzo. 1998. Weakness in the intensive care unit: Differential diagnosis. Progress in Anesthesiology XII, 127-155.

Tinker, D.B., H.J. Harlow, T.D.I. Beck. 1998. Protein use and muscle-fiber changes in freeranging, hibernating black bears. Physiological Zoology 71:414-423.

Widrick, J.J., K.M. Norenbers, J.G. Romatowski, C.A. Blaser. 1998. Force-velocit-power and force-pCa relationship of human soleus fibers after 17 days of bed rest. Journal of Applied Physiology 85:1949-1956. 